\title{
The effects of direct and vicarious nonreward upon instrumental performance'
}

\author{
JOHN H. WHITELEY', UNIVERSITY OF WESTERN ONTARIO \\ THOMAS J. RYAN, CARLETON UNIVERSITY, OTTAWA
}

Kindergarten children performed in pairs on a double lever $\left(R_{1}\right.$ and $\left.R_{2}\right)$ apparatus. In group 50:100, Child $A$ received $50 \%$ reward for $R_{1}$ responses and Child $B$ received $100 \%$ reward for $\mathrm{R}_{2}$ responses. In group 100:100 Child $A$ and Child $B$ received $100 \%$ reward for $R_{1}$ and $R_{2}$ responses, respectively. The $R_{1}$ data were contrary to previous findings with rats and children in that Ss rewarded on a $50 \%$ schedule responded more slowly than those who were continuously rewarded.

Higher asymptotic performance for partially as compared with continuously rewarded Ss has been demonstrated with infrahuman (Spence, 1960, Chap. 6) and human Ss (Ryan, 1965). A similar finding has been noted when children perform in the presence of a passively observing peer (Rosenbaum \& Brunning, 1966).

In one study (Ryan, 1965), children performed two successive lever responses, $R_{1}$ and $R_{2}$. On $R_{1}$, Ss who received $50 \%$ reward responded faster than those who received $100 \%$ reward; on $\mathbf{R}_{2}$, where all Ss in both groups received $100 \%$ reward, those who had received $50 \%$ reward on $\mathbf{R}_{1}$ responded faster as compared with the $100 \%$ group. The present investigation replicated the reward conditions of Ryan's study with the exception that the children were seen in pairs. Thus, each child performed in the presence of an observer who actively performed a similar response.

\section{Method}

The Ss were 32 male and 32 female children (6476 months). With one exception, the double-lever apparatus was as described by Ryan (1965). A unique feature was a common goal box which collected marbles from both levers.

Pairs of Ss were matched for sex and age. Child $A$ performed $R_{1}$ and Child $B$ performed $R_{2}$ throughout the experiment. The Ss were told that this was a team game which required filling the common goal box with marbles in order to win a toy. Ss were instructed not to converse during the game. ${ }^{3}$ There were two rewarded practice trials and 36 test trials. Interresponse and intertrial intervals were 5 and $15 \mathrm{sec}$., respectively.

Each pair of Ss was assigned to one of two reinforcement conditions. In group 100:100, each member of a given pair received 100\% reward. In group 50:100, Child A received $50 \%$ reward for $R_{1}$ responses and Child $B$ received $100 \%$ reward for $R_{2}$ responses. For partially rewarded $\mathrm{Ss}$, three reward and three nonreward trials occurred in each block of six trials.
Measures of starting time, from onset of a stimulus light to initial movement of the lever, and movement time, duration of the 15-in. lever pull, were taken on each trial.

\section{Results}

$\mathbf{R}_{1}$ starting and movement times were converted to speeds $(1 / t$ sec.). In a separate analysis for each measure, the between-Ss variables were reward condition (50:100 vs. 100:100) and sex of S. The within-Ss main effect was trial blocks (six blocks of six trials each). The $R_{1}$ movement speeds revealed a significant interaction (Fig. 1) between reward schedule and trial blocks $(F=5.96, d f=5 / 140, p<.01)$. Separate treatment by $S$ analyses, with trial blocks as the treatment variable, were performed for each reward group These revealed that the $R_{1}$ movement speed of group 50:100 increased significantly $(F=4.46, d f=5 / 75, p<$ $.01)$ and that of group 100:100 decreased significantly $(F=2.69, \mathrm{df}=5 / 75, \mathrm{p}<.01)$ over trial blocks. In the analysis of $R_{1}$ starting speeds, three significant interactions were obtained: reward schedule by $\operatorname{sex}(\mathrm{F}=$ 4.97, $\mathrm{d} f=1 / 28, \mathrm{p}<.05)$, reward schedule by trial blocks $(F=2.46, d f=5 / 140, p<.05)$, and reward schedule by trial blocks by $\operatorname{sex}(F=3.11$, df $=5 / 140, p<.05)$. Separate analyses were then performed for males and females with reinforcement schedule and trial blocks as variables. The schedule by trial blocks interaction was significant only for males $(F=3.22$, $\mathrm{df}=5 / 70, p<.05)$. The pattern portrayed by $R_{1}$ starting speeds was similar to that for movement speeds, but only for males.

$R_{2}$ starting and movement speeds were analyzed

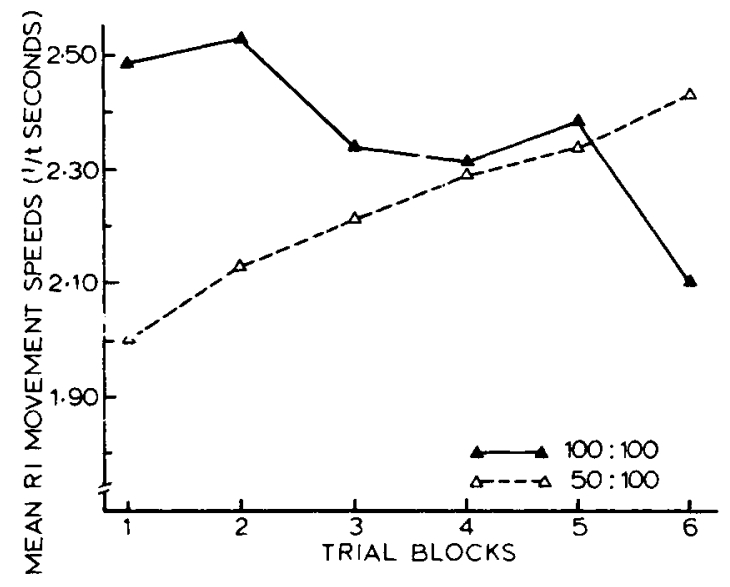

Fig. 1. Mlean $R_{1}$ movement speeds. 


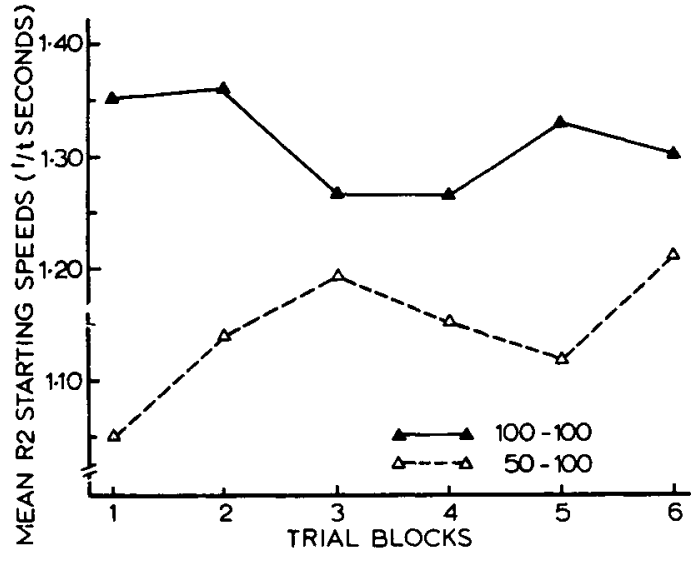

Fig. 2. Mean $\mathbf{R}_{2}$ starting speeds.

in the same manner as $R_{1}$ except that type of trial was added as an additional main effect for within-Ss. For group 50:100 this involved comparisons of $R_{2}$ speeds following reward as compared with nonreward for $R_{1}$. For group 100:100, this comparison involved the corresponding sets of speeds. It is recalled that $R_{1}$ and $\mathbf{R}_{2}$ refer to responses by two different Ss. Type of trial entered into no significant relationships on either starting or movement speeds. Furthermore, the analysis performed on $\mathbf{R}_{2}$ movement speeds revealed no significant effects.

On $R_{2}$ starting speeds, significant interactions were obtained for blocks by $\operatorname{sex}(F=2.99$, df $=5 / 140, p<$ $.05)$ and blocks by reward schedule $(F=3.28$, $\mathrm{df}=$ $5 / 140, p<.01)$. Six separate analyses comparing speeds of the two sex groups at each trial block indicated faster speed for males, as compared with females, only for block $4(F=4.51$, df $=1 / 28, p<.05)$. The interaction between blocks and schedule (Fig. 2) was followed up by computing separate analyses for each group with trial blocks as the main variable. A significant increase in $\mathbf{R}_{2}$ starting speeds over trial blocks was noted for group 50:100 but not for group 100:100. Further analyses, comparing the two reinforcement conditions at each trial block, revealed that $\mathbf{R}_{2}$ starting speeds were significantly faster for group $100: 100$ as compared to $50: 100$ at block $1(\mathrm{~F}=7.54$, $\mathrm{df}=1 / 28, \mathrm{p}<.05)$ and block $5(\mathrm{~F}=4.50, \mathrm{df}=1 / 28, \mathrm{p}<.05)$. Discussion

With respect to the $R_{1}$ data, the interactions ob- tained between reward schedule and trial blocks are unlike those demonstrated for infrahumans (Spence, 1960, Chap. 6), for children performing individually (e.g., Ryan, 1965), or in the presence of a passively observing peer (Rosenbaum \& Bruning, 1966). A tentative explanation of these data suggests that in group 50:100, Child A may have negatively evaluated his performance in relation to Child B. It has been suggested (e.g., Endsley, 1966) that self-blame situations also elicit inhibitory responses. The popularity of the self-blame hypothesis in post hoc explanations (Endsley, 1966; Ford, 1963) demands research to clarify the function of evaluative stimuli in noncontinuous reward situations.

Unless one wished to argue for a vicariously produced self-blame effect, another explanation must be sought for the slower $R_{2}$ starting speeds of group 50:100 relative to group 100:100. Since goal events were more variable in group 50:100 as compared with 100:100, Child B in group 50:100 may focus attention on reward events occurring for Child $A$. The short $R_{1}-R_{2}$ interval would have caught Child $B$ off guard and interfered with $R_{2}$ starting, but not movement speed. Subjective observations by $\mathrm{E}$ plus the failure to demonstrate differences between the two reward groups on $R_{2}$ movement speed add some support to this notion.

\section{References}

Endsley, R. C. Effortfulness and flocking at different distances from the goal as determinants of response speed and amplitude. J. exp. Child Psychol., 1966, 3, 18-30.

Ford, L. H. Reaction to failure as a function of expectancy for success. J. abnorm. soc. Psychol., 1963, 67, 340-348.

Rosenbaum, M. E., \& Bruning, J. L. Direct and vicarious experience of variations in percentage of reinforcement. Child Develpm., 1966, 37, 959-966.

Ryan, T. J. The effects of nonreinforcement and incentive value on response speed. Child Develpm., 1965, 36, 1067-1081.

Spence, K. W. Behavior theory and learning: Selected papers. Englewood Cliffs: Prentice Hall, 1960.

\section{Notes}

1. This study was assisted by National Research Council Grant APB-2 to the second author and by the Children's Psychiatric Research Institute, Londop, Ontario. The authors are indebted to the Board of Education, London, Ontario, for assistance in obtaining subjects.

2. Now at Institute of Child Behavior \& Development, State University of Iowa.

3. In a preliminary study $(\mathrm{N}=80)$ communication within pairs was allowed and no significant differences occurred between reward groups. 